\title{
Addressing the need for rapid treatment of agitation in schizophrenia and bipolar disorder: focus on inhaled loxapine as an alternative to injectable agents
}

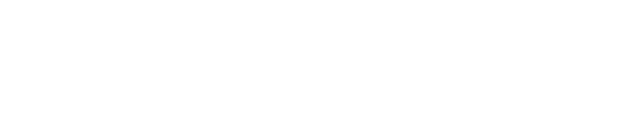

\section{Leslie Citrome}

Department of Psychiatry and Behavioral Sciences, New York Medical College, Valhalla, NY, USA
Correspondence: Leslie Citrome

I I Medical Park Drive, Suite 106,

Pomona, NY 10970, USA

$\mathrm{Tel}+$ I 845362208 I

Fax +l 8453628745

Email citrome@cnsconsultant.com

\begin{abstract}
Agitation (excessive motor or verbal activity) can be associated with schizophrenia or bipolar mania, and can further escalate into aggressive behavior and potentially lead to injuries in patients and staff. Medications used to treat agitation include antipsychotics and benzodiazepines, usually administered intramuscularly when rapid action is desired. Loxapine, a first-generation antipsychotic, has recently been reformulated into an inhaled powder that allows for direct administration to the lungs, resulting in rapid absorption into the systemic circulation. Administered via a single-use device, inhaled loxapine was tested in randomized controlled trials in agitation associated with schizophrenia or bipolar mania; doses of $5 \mathrm{mg}$ and $10 \mathrm{mg}$ were found to be efficacious, with an apparent dose response. In the Phase III studies, number needed to treat versus placebo for a $\geq 40 \%$ reduction from baseline on the Positive and Negative Syndrome Scale - Excited Component (PANSS-EC) at 2 hours was three for patients with bipolar disorder, and five for $5 \mathrm{mg}$ and four for $10 \mathrm{mg}$ for patients with schizophrenia, with effect sizes comparable to what has been observed in analogous studies of intramuscular injection of antipsychotics or lorazepam. Separation from placebo on the PANSS-EC was as early as 10 minutes postinhalation, the first time point where this was measured. Dysgeusia was the most commonly encountered spontaneously reported adverse event. Adverse events related to extrapyramidal symptoms and akathisia were relatively rare. Spirometry studies identified the potential for bronchospasm particularly in persons with asthma. Because of concerns over pulmonary safety, inhaled loxapine is restricted to use in hospitals and patients need to be prescreened for the presence of pulmonary disease, as well as monitored for signs and symptoms of bronchospasm for 1 hour postdose administration, as per a Food and Drug Administrationmandated Risk Evaluation and Mitigation Strategy.
\end{abstract}

Keywords: agitation, antipsychotic, bipolar disorder, inhaled loxapine, mania, schizophrenia

\section{Introduction}

Agitation (excessive motor or verbal activity) associated with untreated schizophrenia or bipolar mania is not uncommon and can further escalate into aggressive behavior and potential for patient and staff injuries. ${ }^{1,2}$ Agitation associated with psychosis is a frequent reason for emergency department visits, admission to a psychiatric in-patient ward, and continued hospitalization. Despite treatment of the underlying psychiatric condition, intermittent agitated behavior can remain problematic.

Differential diagnosis of agitated behavior in a person with known schizophrenia or bipolar disorder can be complex as there can be multiple causes, any of which can 
be present at the same time and can also differ from episode to episode..$^{3-7}$ There may be co-occurring substance use or intoxication, intrusive hallucinations or paranoid delusions, neuropsychiatric deficits that result in overall poor impulse control, a chaotic environment that lends itself to behavior dyscontrol, or frank psychopathy. An underlying somatic illness may be present resulting in a delirium or other alterations in a person's mental state. Iatrogenic causes of agitation include akathisia, a distressing sensation of being unable to sit still, that can be induced by antipsychotics and antidepressants. ${ }^{8}$ Akathisia can be easily missed, and if mistaken for worsening psychosis may lead to increases in antipsychotic dosages, resulting in worsening akathisia. ${ }^{9}$

The clinical management of agitation associated with schizophrenia or bipolar mania includes behavioral and psychological techniques, ${ }^{10}$ as well as the use of nonspecific sedating agents such as benzodiazepines and/or antipsychotics that also at the same time would be expected to treat the underlying psychiatric condition. ${ }^{11}$ Goals of treatment of agitation include calming the patient as rapidly as possible, decreasing the likelihood of harm to self or others, allowing diagnostic tests or procedures to take place, attenuating psychosis, and decreasing the need for seclusion or restraint (a time of high risk for patients and staff injury). ${ }^{1}$ Sleep, in itself, is not desirable when evaluating the patient; excessive sedation results in the need for constant observation, assistance in toileting, and excessive burdens being placed on nursing staff resources.

This review focuses on the pharmacological management of agitation associated with schizophrenia or bipolar mania, with an emphasis on a new intervention, an inhaled formulation of loxapine, a first-generation antipsychotic.

\section{Current pharmacological treatments for agitation}

For a medication to be clinically useful for the treatment of agitation it must have a predictably high response rate for inducing calm and be relatively tolerable. A rapid onset of action usually requires a medication/formulation to have a short time to maximum concentration (ordinarily $<60$ minutes), and this usually requires rapid entry to the systemic circulation. Adverse effects such as excessive sedation, hypotension, respiratory depression, acute dystonia, or akathisia will complicate patient management and potentially impact the willingness of patients to adhere to similar medications in the future.

At the present time, intramuscular lorazepam is often used as an antiagitation agent. In contrast to other benzodiazepines, lorazepam is reliably absorbed when injected into the muscle, has a short half-life, and has no active metabolites. ${ }^{11}$ However, respiratory depression and, rarely, paradoxical reactions can occur. Although the administration of lorazepam can potentially treat an underlying withdrawal from alcohol, prolonged continued use of lorazepam can lead to tolerance and ultimately has no or little effect on core symptoms of psychosis. First-generation antipsychotics have been used intramuscularly to treat agitation, including chlorpromazine ${ }^{12}$ and haloperidol. ${ }^{13,14}$ Unfortunately, intramuscular chlorpromazine has been associated with hypotension and anticholinergic effects, as well as a reduction in the seizure threshold. Haloperidol is commonly associated with extrapyramidal adverse effects and akathisia. Moreover, the use of anticholinergic medication to counteract tremor and rigidity can further impair the patient's already compromised cognitive abilities. ${ }^{15}$

Intramuscular preparations of ziprasidone, olanzapine, and aripiprazole are available for the treatment of acute agitation and they are generally better tolerated than chlorpromazine or haloperidol. ${ }^{16}$ Extrapyramidal adverse effects and akathisia can thus be minimized. Continued treatment with the oral formulations of these agents can be accomplished and offer the potential for effective outcomes. Effect sizes for antiagitation response for intramuscular ziprasidone, olanzapine, and aripiprazole are comparable to the effect sizes demonstrated for haloperidol and lorazepam. ${ }^{16}$ In guidelines developed by the American Association for Emergency Psychiatry, antipsychotics are recommended over benzodiazepines for psychosis-driven agitation in a patient with a known psychiatric disorder (eg, schizophrenia, schizoaffective disorder, bipolar disorder) because they address the underlying psychosis. ${ }^{17}$ In addition, secondgeneration antipsychotics with supportive data for their use in acute agitation are preferred over haloperidol either alone or with an adjunctive medication; if the patient cannot cooperate with oral medications, intramuscular ziprasidone or intramuscular olanzapine is preferred for acute control of agitation. $^{17}$

The commonly used rapidly-acting pharmacologic options for acute agitation are outlined in Table 1.

\section{Emerging therapies: inhaled loxapine}

Loxapine is a first-generation antipsychotic that has been reformulated into an inhaled powder that allows for direct administration to the lungs, resulting in rapid absorption into the systemic circulation. Inhaled loxapine 
Table I Rapidly-acting pharmacologic options for acute agitation

\begin{tabular}{|c|c|c|c|}
\hline Agent & Dose (mg) & Advantages & Disadvantages \\
\hline Lorazepam & $0.5-2.0$ & $\begin{array}{l}\text { Reliably absorbed when injected into } \\
\text { the muscle; short half-life; no active } \\
\text { metabolites; can potentially treat alcohol } \\
\text { withdrawal; relatively inexpensive }\end{array}$ & $\begin{array}{l}\text { No antipsychotic effect; potential for respiratory } \\
\text { depression; risk for behavioral disinhibition } \\
\text { (paradoxical reaction); development of tolerance }\end{array}$ \\
\hline Haloperidol & $0.5-7.5$ & $\begin{array}{l}\text { Antipsychotic effect over time; relatively } \\
\text { inexpensive }\end{array}$ & $\begin{array}{l}\text { Akathisia; dystonia; will not treat underlying alcohol } \\
\text { withdrawal }\end{array}$ \\
\hline Ziprasidone & $10-20$ & $\begin{array}{l}\text { Antipsychotic effect over time; favorable } \\
\text { extrapyramidal symptom profile } \\
\text { compared to first-generation } \\
\text { antipsychotics }\end{array}$ & $\begin{array}{l}\text { Explicit warning in product labeling regarding } \\
\text { prolongation of the QTc interval; will not treat } \\
\text { underlying alcohol withdrawal; relatively more costly } \\
\text { but availability of generic product will impact on price }\end{array}$ \\
\hline Olanzapine & $\begin{array}{l}\text { I0 ( } 5 \text { or } 7.5 \\
\text { when clinically } \\
\text { warranted })\end{array}$ & $\begin{array}{l}\text { Antipsychotic effect over time; } \\
\text { favorable extrapyramidal symptom } \\
\text { profile compared to first-generation } \\
\text { antipsychotics }\end{array}$ & $\begin{array}{l}\text { Concomitant administration of intramuscular } \\
\text { olanzapine and parenteral benzodiazepine is not } \\
\text { recommended due to the potential for excessive } \\
\text { sedation and cardiorespiratory depression; weight } \\
\text { gain over time; will not treat underlying alcohol } \\
\text { withdrawal; relatively more costly but availability of } \\
\text { generic product will impact on price }\end{array}$ \\
\hline Aripiprazole & 9.75 & $\begin{array}{l}\text { Antipsychotic effect over time; } \\
\text { favorable extrapyramidal symptom } \\
\text { profile compared to first-generation } \\
\text { antipsychotics }\end{array}$ & $\begin{array}{l}\text { No dosage adjustment of aripiprazole is required when } \\
\text { administered concomitantly with lorazepam but the } \\
\text { intensity of sedation was greater with the combination } \\
\text { as compared to that observed with aripiprazole alone } \\
\text { and the orthostatic hypotension observed was greater } \\
\text { with the combination as compared to that observed } \\
\text { with lorazepam alone; will not treat underlying } \\
\text { alcohol withdrawal; relatively more costly and remains } \\
\text { under patent exclusivity at present }\end{array}$ \\
\hline
\end{tabular}

at a $10 \mathrm{mg}$ dose was approved by the US Food and Drug Administration (FDA) December 21, 2012 for the acute treatment of agitation associated with schizophrenia or bipolar I disorder in adults. ${ }^{18,19}$ This was followed by approval by the European Medicines Agency (EMA) on February 20, 2013 for the dose strengths of $5 \mathrm{mg}$ and $10 \mathrm{mg} \cdot{ }^{20,21}$ EMA labeling notes that the single dose inhaler of loxapine $5 \mathrm{mg}$ delivers $4.5 \mathrm{mg}$ loxapine, and that the $10 \mathrm{mg}$ inhaler delivers $9.1 \mathrm{mg} .{ }^{21}$ The indication in EMA labeling is for rapid control of mild to moderate agitation in adult patients with schizophrenia or bipolar disorder. Although the FDA has approved inhaled loxapine $10 \mathrm{mg}$ for only a single dose within any 24-hour period, the EMA allows for two doses of either 5 or $10 \mathrm{mg}$, separated by 2 hours. Similar risk mitigation procedures regarding the potential for bronchospasm are required by both the FDA and EMA, including the restriction that inhaled loxapine is to be used only in health care facilities.

The efficacy and safety of inhaled loxapine for agitation is supported by a Phase II trial in patients with schizophrenia, ${ }^{22}$ a Phase III trial in patients with schizophrenia, ${ }^{23}$ and in a Phase III trial in patients with bipolar mania. ${ }^{24}$ Detailed information on the clinical development of inhaled loxapine has been made available by the manufacture ${ }^{25}$ and regulatory authorities. ${ }^{26,27}$ Prior systematic reviews can be found elsewhere. ${ }^{28,29}$

\section{Pharmacology, mode of action, and pharmacokinetics of inhaled loxapine}

Inhaled loxapine is administered by having the patient take a breath using a handheld single-use device. No hand/breath coordination is required. Upon inhalation a sensor is activated and initiates the production of a thermally-generated condensation aerosol that contains $1-3.5 \mu$ particles of loxapine which enter the respiratory track in $<1$ second. ${ }^{30,31}$ No forceful inhalation is required. Purity of the emitted medication is greater than $99.5 \%$ and the emitted dose is approximately $90 \%$ of the drug contained in the device. ${ }^{30,31}$ There are no excipients. A relatively small amount (11\%) is deposited into the oropharyngeal region. ${ }^{32}$

Similar to all available antipsychotics, loxapine is an antagonist at the dopamine D2 receptor. Loxapine also has clinically relevant serotonin 5-HT2A receptor antagonism. ${ }^{33}$ As per the product label, affinities for serotonin 5-HT2A and dopamine D1, D2, D3, and D4 receptors have Ki values of $2 \mathrm{nM}, 18 \mathrm{nM}, 10 \mathrm{nM}, 21 \mathrm{nM}$, and $9 \mathrm{nM}$, respectively. ${ }^{19}$ Some of the adverse effects of loxapine may be related to 
the antagonism of histamine $\mathrm{H} 1$ (somnolence), muscarinic M1 (anticholinergic), and adrenergic $\alpha 2$ (orthostatic hypotension) receptors (Ki values of $15 \mathrm{nM}, 117 \mathrm{nM}$, and $250 \mathrm{nM}$, respectively). ${ }^{19}$ The 7-OH loxapine metabolite of loxapine has a five-fold higher affinity for the dopamine D2 receptor compared with loxapine, and thus it may contribute to the clinical effect of the drug. ${ }^{34}$

Detailed pharmacokinetic information is available in a published study of single-dose inhaled loxapine $(0.625,1.25$, $2.5,5.0$, or $10 \mathrm{mg}$ ) administered to 50 healthy volunteers. ${ }^{34}$ Product labeling summarizes the key variables for the $10 \mathrm{mg}$ dose: mean (standard deviation) area under the curve

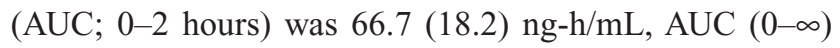
188 (47) ng-h/mL, maximum concentration 257 (219) ng/mL, half-life 7.61 (1.87) hours, and median time to maximum concentration $1.13(25 \%, 1 ; 75 \%, 2)$ minutes. ${ }^{19}$ The mean plasma loxapine concentrations following administration of inhaled loxapine were linear over the clinical dose range; AUC and maximum concentration increased in a dosedependent manner.

Loxapine is removed rapidly from the plasma and distributed in tissues. ${ }^{19}$ In animal studies, an initial preferential distribution in the lungs, brain, spleen, heart, and kidney was observed after oral administration. ${ }^{19}$ The concentration of loxapine and its metabolites after the initial distribution phase is similar to that of oral loxapine. ${ }^{34}$ Loxapine is $96.6 \%$ bound to human plasma proteins. ${ }^{19}$

Loxapine undergoes extensive metabolism in the liver following oral administration, with multiple metabolites formed. ${ }^{19}$ The main metabolic pathways include: (1) hydroxylation to form 8-OH-loxapine by cytochrome P450 1A2 and 7-OH-loxapine by cytochrome P450 3A4 and cytochrome P450 2D6; (2) N-oxidation to form loxapine N-oxide by flavonoid monoamine oxidases; and (3) demethylation to form amoxapine. ${ }^{19}$ Because of the presence of multiple metabolic pathways, the risk of metabolic interactions is minimal. For inhaled loxapine, the order of metabolites observed in people based on systemic exposure was 8-OH-loxapine $>>$ loxapine $\mathrm{N}$-oxide, 7-OHloxapine $>$ amoxapine. ${ }^{19}$ Plasma levels of $8-\mathrm{OH}$-loxapine are similar to those of the parent compound. Among the subjects receiving $5 \mathrm{mg}$ and $10 \mathrm{mg}$, exposure to the metabolites of loxapine as a percentage of exposure to the parent compound were approximately $9 \%$ for $7-\mathrm{OH}$ loxapine, $53 \%$ for $8-\mathrm{OH}$ loxapine, and $4 \%$ for amoxapine. ${ }^{34}$ Amoxapine itself is approved by the FDA for depression. ${ }^{35}$ Loxapine is not extensively metabolized in the lungs. Cigarette smoking does not appear to significantly alter the absorption or metabolism of inhaled loxapine, ${ }^{30}$ with geometric mean ratios for smokers versus nonsmokers of $92 \%, 85 \%$, and $99 \%$ for AUC (0-2 hours), AUC ( $0-\infty)$, and maximum concentration, respectively; ${ }^{19}$ thus, no dosage adjustment is recommended based on smoking status. ${ }^{19}$

Excretion of inhaled loxapine occurs mainly in the first 24 hours. ${ }^{19}$ Metabolites are excreted in the urine in the form of conjugates and in the feces unconjugated.

In vitro studies indicated that loxapine was not a substrate for P-glycoprotein; however, loxapine inhibited P-glycoprotein. ${ }^{19}$

There were no clinically significant differences in loxapine pharmacokinetics following administration of inhaled loxapine in subgroups based on age, weight, body mass index, gender, or race. ${ }^{19}$

\section{Efficacy, tolerability, and safety of inhaled loxapine Efficacy}

Table 2 summarizes the design of the randomized controlled trials conducted in persons with schizophrenia or bipolar mania. All studies were double-blind and compared inhaled loxapine 5 or $10 \mathrm{mg}$ versus inhaled placebo. During the screening period, a study nurse demonstrated to each patient how to use the device. Inclusion criteria included clinically relevant agitation, as measured by a minimum score of 14 on the Positive and Negative Syndrome Scale - Excited Component (PANSS-EC), consisting of the PANSS items of tension, excitement, hostility, uncooperativeness, and poor impulse control (each item rated from one [absent] to seven [extreme]) and a score of at least four (moderate) on at least one item. Excluded were patients who had a positive urine drug screen. ${ }^{28}$ Intramuscular lorazepam was allowed as a rescue medication at any time after the inhalation in the Phase II study or after a second dose of the randomized medication in the Phase III studies. Table 3 summarizes the efficacy results. Reduction of agitation for patients with schizophrenia and bipolar mania was rapid and robust. In the Phase III trials, number needed to treat $(\mathrm{NNT})^{36}$ to achieve $\geq 40 \%$ reduction from baseline on the PANSS-EC at 2 hours after dose administration was four $(95 \%$ confidence interval [CI] 3-6) for inhaled loxapine $10 \mathrm{mg}$ versus placebo for agitation associated with schizophrenia, and three (95\% CI 2-3) for agitation associated with bipolar mania. ${ }^{29}$ This compares favorably when examining the analogous outcomes for intramuscular ziprasidone, olanzapine, or aripiprazole with NNT values of three (95\% CI 2-4), three $(95 \%$ CI 2-3), and five (95\% CI 4-8), respectively, as well as for 


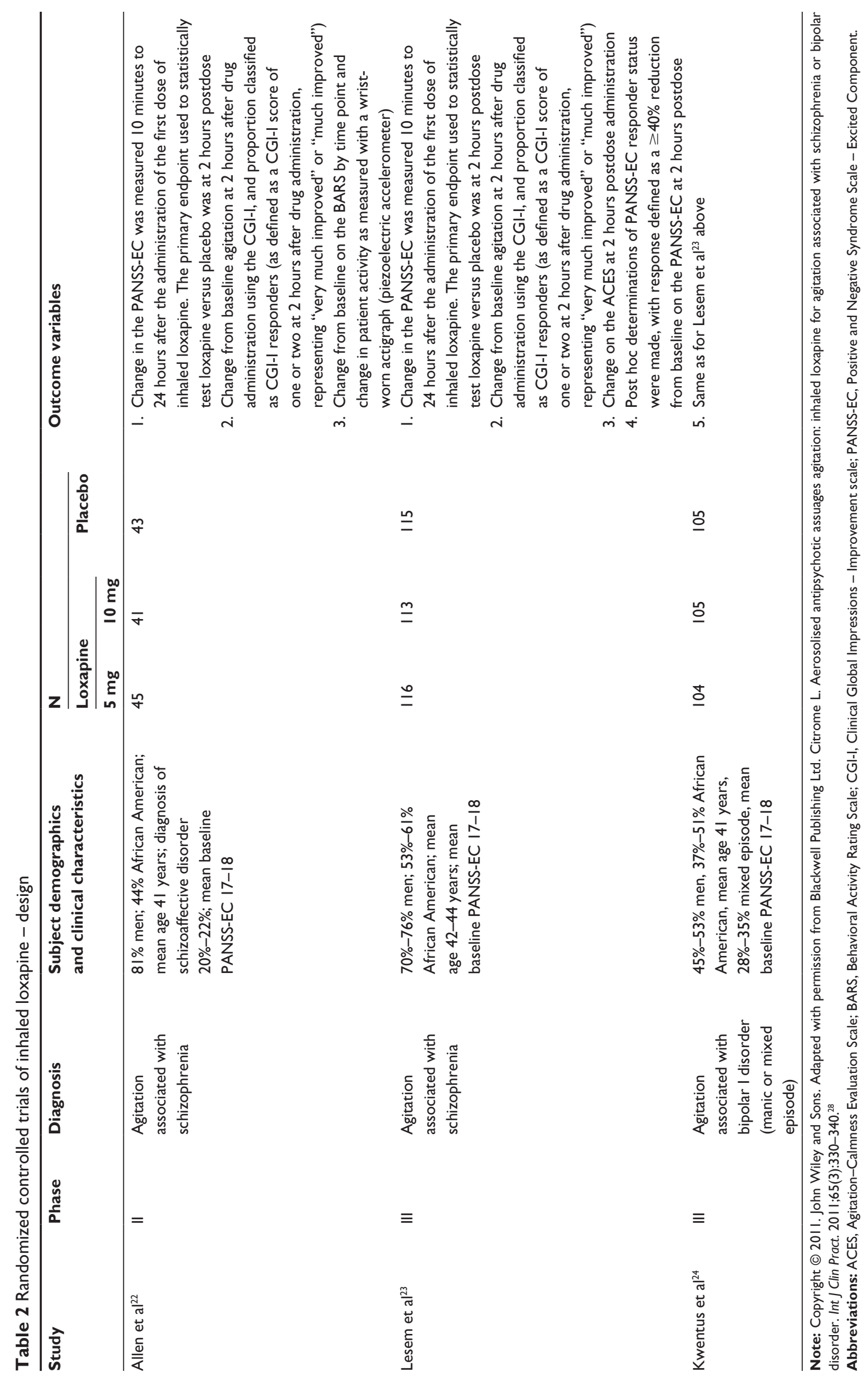




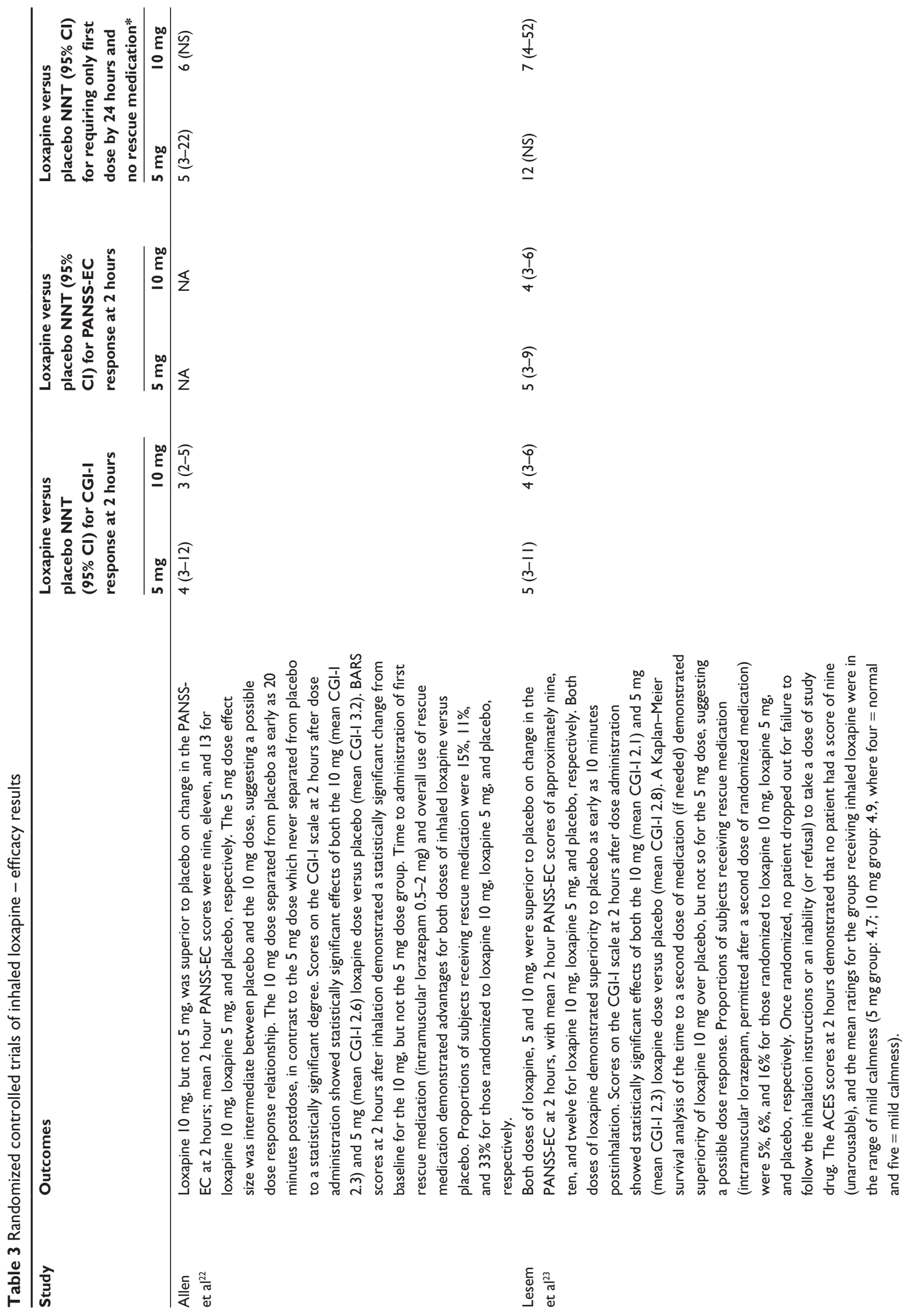




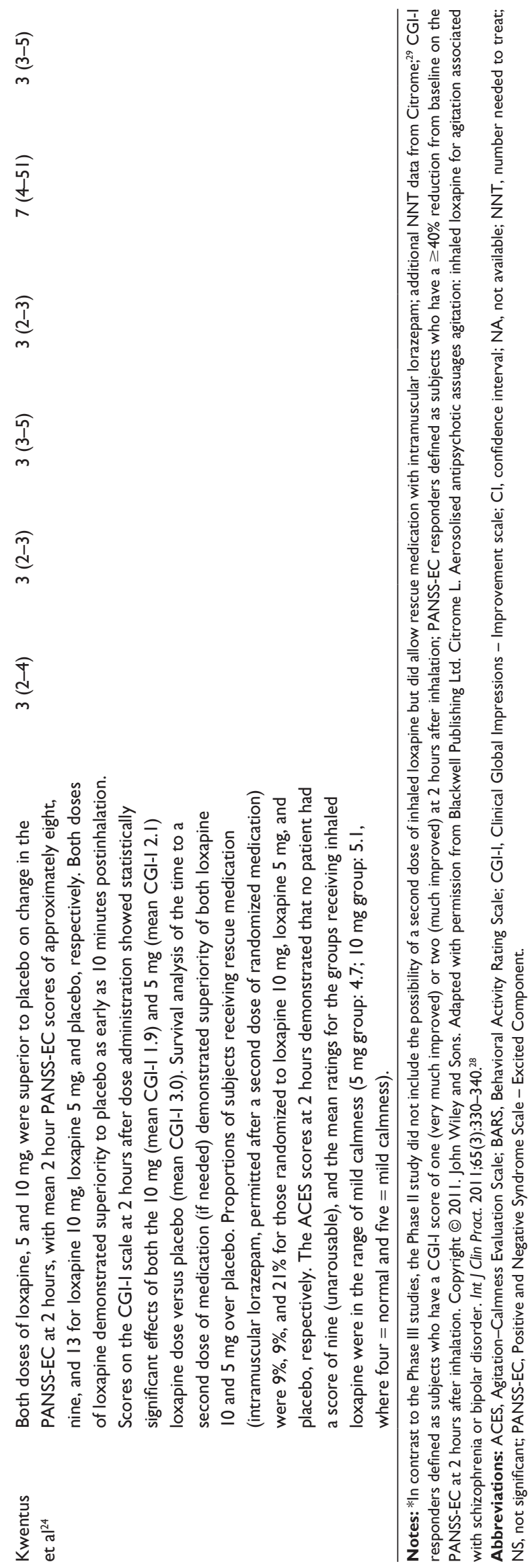

intramuscular haloperidol and lorazepam, with NNT values of four (95\% CI 3-5) and four (95\% CI 3-7), respectively. ${ }^{16}$ NNT for inhaled loxapine Clinical Global Impressions Improvement scale responders mirrors that for PANSS-EC responders. ${ }^{29}$ In the Phase III trials for inhaled loxapine, the NNT values for Clinical Global Impressions - Improvement scale responders, PANSS-EC responders, and requirement for an additional dose and/or rescue medication point to a dose response relationship where inhaled loxapine $10 \mathrm{mg}$ appears superior to $5 \mathrm{mg}$ (Table 3 ). When examining each individual item on the PANSS-EC in each of the Phase III trials, every item improved with treatment, starting at 10-20 minutes after dosing. ${ }^{37}$ In addition, inhaled loxapine appears to reduce agitation equally well in patients with higher or lower levels of agitation at baseline, as defined by a baseline PANSS-EC $>17$ versus $\leq 17 .{ }^{37}$

\section{Tolerability}

As per product labeling, ${ }^{19}$ the most common adverse reactions (incidence $\geq 2 \%$ and greater than placebo) were dysgeusia (distortion of the sense of taste or a bad taste in the mouth), sedation, and throat irritation. These specific adverse events and extrapyramidal symptoms are outlined in Table 4 for the pooled Phase II and III study results. ${ }^{25}$ Number needed to harm $(\mathrm{NNH})^{38}$ for dysgeusia for inhaled loxapine versus placebo is 16 (95\% CI 10-58) for the $5 \mathrm{mg}$ dose and eleven (95\% CI 7-23) for the $10 \mathrm{mg}$ dose. NNH for throat irritation is statistically significant only for the $10 \mathrm{mg}$ dose (44; 95\% CI 23-472). NNH for sedation/somnolence is not statistically significant for either $5 \mathrm{mg}$ or $10 \mathrm{mg}$ of inhaled loxapine. Extrapyramidal symptoms including akathisia were sufficiently uncommon to result in statistically nonsignificant values for NNH versus placebo. This extrapyramidal symptom tolerability profile appears superior to that observed for intramuscular haloperidol in clinical trials, with $\mathrm{NNH}$ values of haloperidol $7.5 \mathrm{mg}$ versus placebo as robust as six (95\% CI 4-23) for Parkinsonism. ${ }^{16}$

\section{Pulmonary safety}

The product label has a bolded boxed warning in place stating that inhaled loxapine "can cause bronchospasm that has the potential to lead to respiratory distress and respiratory arrest," 19 although complications of bronchospasm were not observed in the clinical trial program. Contraindications to the use of inhaled loxapine include current diagnosis or history of asthma, chronic obstructive pulmonary disease (COPD), or other lung disease associated with bronchospasm; acute respiratory signs/symptoms (eg, wheezing); current use 
Table 4 Randomized controlled trials of inhaled loxapine - pooled tolerability results: incidence and number needed to harm versus placebo ( $95 \%$ confidence interval)

\begin{tabular}{|c|c|c|c|c|c|}
\hline \multirow[t]{2}{*}{ Adverse event } & \multirow{2}{*}{$\frac{\text { Placebo }(\mathrm{N}=263)}{\mathrm{n}(\%)}$} & \multicolumn{2}{|c|}{ Loxapine 5 mg $(\mathrm{N}=265)$} & \multicolumn{2}{|c|}{ Loxapine $10 \mathrm{mg}(\mathrm{N}=\mathbf{2 5 9})$} \\
\hline & & n (\%) & NNH $(95 \% \mathrm{Cl})$ & n (\%) & NNH $(95 \% \mathrm{Cl})$ \\
\hline Dysgeusia & $13(4.9)$ & $30(11.3)$ & $16(10-58)$ & $37(14.3)$ & II (7-23) \\
\hline Sedation/somnolence & $25(9.5)$ & $32(12.1)$ & 39 (NS) & $31(12.0)$ & $4 \mathrm{I}(\mathrm{NS})$ \\
\hline Throat irritation & $\mathrm{I}(0.4)$ & $2(0.8)$ & 267 (NS) & $7(2.7)$ & $44(23-472)$ \\
\hline $\begin{array}{l}\text { Any extrapyramidal symptom } \\
\text { adverse event }\end{array}$ & I (0.4) & $5(1.9)$ & 67 (NS) & $4(1.5)$ & 86 (NS) \\
\hline Akathisia & 0 & $\mathrm{I}(0.4)$ & 265 (NS) & I $(0.4)$ & 259 (NS) \\
\hline
\end{tabular}

Abbreviations: $\mathrm{Cl}$, confidence interval; $\mathrm{NNH}$, number needed to harm; NS, not significant.

of medications to treat airways disease, such as asthma or COPD; history of bronchospasm following treatment with inhaled loxapine; and known hypersensitivity to loxapine or amoxapine. ${ }^{19}$ Prior to administering inhaled loxapine, patients must be screened for a history of pulmonary disease, and examined by chest auscultation for respiratory abnormalities such as wheezing. After administration, patients are required to be monitored for signs and symptoms of bronchospasm at least every 15 minutes for at least 1 hour. These and other requirements are articulated in the FDA-mandated Risk Evaluation and Mitigation Strategy designed to ensure that the benefits of the drug outweigh the risk of bronchospasm..$^{18,19,39}$ Inhaled loxapine is to be made available in the US only in an enrolled health care facility that has immediate access onsite to equipment and personnel trained to manage acute bronchospasm, including advanced airway management (intubation and mechanical ventilation). ${ }^{19}$ Wholesalers and distributors in the US that distribute inhaled loxapine must also enroll in the program and distribute only to enrolled health care facilities. The manufacturer is required to submit to the FDA all initial and follow-up adverse drug experiences pertaining to respiratory events, including but not limited to the following: asthma, COPD, bronchospasm, wheezing, and shortness of breath. Also required are reports of respiratory events requiring intervention, such as treatment with a bronchodilator or other rescue medications, oxygen, intubation, mechanical ventilation (invasive and noninvasive), an emergency department visit/prolongation of an existing visit, or hospitalization/prolongation of an existing hospitalization.

In the clinical trial program, among the 1095 study subjects without active airway disease who received inhaled loxapine, one $(0.09 \%)$ required treatment with albuterol for bronchospasm. Cough was the most common airway adverse event in the inhaled loxapine-treated subjects $(19 / 1095 ; 1.7 \%)$, and these events were all rated as mild $(\mathrm{N}=18)$ or moderate $(\mathrm{N}=1)$ and were self-limiting. Among inhaled loxapine-treated patients in the Phase II/III agitated patient population, there were four airway adverse events; all were mild or moderate, none was judged to be a serious adverse event, and only one required intervention (the use of albuterol noted above), which led to resolution. Approximately $87 \%$ of patients in the Phase II/III agitated patient population were current or ex-smokers, with $22 \%$ having $\geq 20$ pack-years of cigarette use. ${ }^{25}$ Product labeling ${ }^{19}$ notes bronchospasm (which includes reports of wheezing, shortness of breath, and cough) occurred more frequently in the inhaled loxapine group compared to the placebo group: $0 \%(0 / 263)$ in the placebo group and

Table 5 Inhaled loxapine in subjects with asthma or chronic obstructive pulmonary disease - pulmonary findings

\begin{tabular}{|c|c|c|c|c|c|c|}
\hline \multirow[t]{3}{*}{ Outcome } & \multicolumn{3}{|l|}{ Asthma } & \multicolumn{3}{|l|}{ COPD } \\
\hline & \multirow{2}{*}{$\begin{array}{l}\text { Placebo } \\
(\mathrm{N}=26) \\
n(\%)\end{array}$} & \multicolumn{2}{|c|}{$\begin{array}{l}\text { Loxapine } 10 \mathrm{mg} \\
(\mathrm{N}=26)\end{array}$} & \multirow{2}{*}{$\begin{array}{l}\text { Placebo } \\
(\mathbf{N}=27) \\
n(\%)\end{array}$} & \multicolumn{2}{|c|}{$\begin{array}{l}\text { Loxapine } 10 \mathrm{mg} \\
(\mathrm{N}=26)^{*}\end{array}$} \\
\hline & & n (\%) & NNH $(95 \% \mathrm{Cl})$ & & n (\%) & NNH $(95 \% \mathrm{Cl})$ \\
\hline$\geq 10 \%$ reduction in $\mathrm{FEV}$, & $3(12)$ & $22(85)$ & $2(2-2)$ & $18(67)$ & $20(80)$ & 8 (NS) \\
\hline$\geq 20 \%$ reduction in $\mathrm{FEV}$ & $\mathrm{I}(4)$ & II (42) & $3(2-6)$ & $3(11)$ & $10(40)$ & $4(2-16)$ \\
\hline Any airway adverse event & $3(12)$ & $14(54)$ & $3(2-6)$ & $3(11)$ & $5(19)$ & 13 (NS) \\
\hline Adverse event of bronchospasm & I (4) & $7(27)$ & $5(3-23)$ & I (4) & 0 & NA \\
\hline Albuterol use & $3(12)$ & $14(54)$ & $3(2-6)$ & $4(15)$ & $6(23)$ & 13 (NS) \\
\hline
\end{tabular}

Note: *Spirometry data not available for one subject, thus $\mathrm{N}=25$.

Abbreviations: $\mathrm{Cl}$, confidence interval; COPD, chronic obstructive pulmonary disease; $\mathrm{FEV}_{1}$, volume of air exhaled in the first second of a forced exhalation starting from a position of full inspiration; NA, not applicable; $\mathrm{NNH}$, number needed to harm; NS, not significant. 
$0.8 \%(2 / 259)$ in the inhaled loxapine $10 \mathrm{mg}$ group for an $\mathrm{NNH}$ versus placebo of 130 (not significant). Supplementing this information are the results of three Phase I spirometry studies comparing loxapine $10 \mathrm{mg}$ versus placebo in nonagitated subjects: a study in healthy nonsmoking volunteers, another in subjects with mild or moderate persistent asthma, and a third study in subjects with COPD, most (89\%) with moderate or severe disease. ${ }^{25}$ For each study, the primary safety measure was the volume of air exhaled in the first second of a forced exhalation starting from a position of full inspiration $\left(\mathrm{FEV}_{1}\right)$. No clinically relevant effect on airways in the study of healthy volunteers was observed but this was not the case for subjects with asthma or COPD. Table 5 summarizes the key findings, with data from the manufacture ${ }^{25}$ and $\mathrm{NNH}$ values previously reported..$^{29}$ The $\mathrm{NNH}$ for reduction in $\mathrm{FEV}_{1}$ values was more pronounced in the asthma study compared to the COPD study. $\mathrm{FEV}_{1}$ values returned to within $10 \%$ of baseline by the end of the 34-hour evaluation period for all participants in the asthma study. All airway adverse events in these subjects with asthma or COPD were mild or moderate. Regarding the adverse event of bronchospasm, this appeared to be associated with asthma and not COPD. All respiratory signs or symptoms requiring treatment in the Phase I asthma and COPD studies were readily managed with an inhaled bronchodilator.

\section{Other safety issues}

Inhaled loxapine did not prolong the electrocardiogram QT interval, as assessed in a thorough QT study. ${ }^{19}$ Potential drug-drug interactions include the possibility for respiratory depression, hypotension, profound sedation, and syncope when combined with other central nervous system depressants. ${ }^{19}$ Because inhaled loxapine has anticholinergic activity, the concomitant use of inhaled loxapine with other anticholinergic drugs can increase the risk of anticholinergic adverse reactions such as exacerbation of glaucoma and urinary retention. ${ }^{19}$ Antipsychotic class-level warnings and precautions include neuroleptic malignant syndrome, hypotension and syncope, seizure, potential for cognitive and motor impairment, and cerebrovascular adverse reactions/ increased mortality in elderly patients with dementia-related psychosis. ${ }^{19,40}$

\section{Patient-focused perspectives}

Careful consideration of a patient's individual preferences and values are an important component in the practice of evidence-based medicine ${ }^{41}$ and helps to enhance the therapeutic alliance. For patients who have an aversion to injections and/or who perceive them to be a form of forced treatment, inhaled loxapine may be a useful alternative to intramuscular injection when rapid control of agitation is required. Further research examining this would be helpful, and should include measures of quality of life, patient satisfaction and acceptability, and adherence.

\section{Regulatory issues}

In addition to the FDA-mandated Risk Evaluation and Mitigation Strategy, the FDA has also required the conduct of a large, nonrandomized, open-label, postmarketing observational study to assess the risks of bronchospasm and related respiratory adverse events and serious outcomes (eg, hospitalization, intubation, mechanical ventilation, or rescue medication for the management of respiratory reactions) associated with inhaled loxapine. ${ }^{18}$ Pediatric studies for the acute treatment of agitation associated with schizophrenia or bipolar I disorder in patients aged $10-17$ years are also being required..$^{18}$

\section{Conclusion and place in therapy}

Inhaled loxapine is a possible alternative to parenteral injections of other antipsychotics for the rapid reduction of agitation in patients with schizophrenia or bipolar disorder. Because of pulmonary safety concerns, the FDA has mandated a Risk Evaluation and Mitigation Strategy restricting the use of inhaled loxapine to enrolled hospitals and placing a limit on the number of administrations to a single $10 \mathrm{mg}$ dose in any one 24-hour period. In Europe, similar restrictions are in place but both the $5 \mathrm{mg}$ and $10 \mathrm{mg}$ doses are approved and patients may receive up to two doses, spaced 2 hours apart. Efficacy in terms of speed and degree of reduction of agitation is comparable to that for intramuscular injections of first- or secondgeneration antipsychotics, or lorazepam. Dysgeusia is the most frequently encountered adverse event (incidence with $10 \mathrm{mg}$ is $14 \%$ versus $5 \%$ for placebo, yielding an $\mathrm{NNH}$ of eleven). Extrapyramidal adverse events or akathisia adverse events are relatively rare. Because inhaled loxapine is selfadministered under medical supervision, it is unlikely to be considered during emergencies when a patient is actively refusing medication treatment. However, patients may express a preference for inhaled loxapine over intramuscular injection of an alternative antiagitation agent when rapid reduction of agitation is desired and the appearance of coercion is problematic.

\section{Disclosure}

No writing assistance was utilized in the production of this review. In the past 36 months Leslie Citrome has engaged 
in collaborative research with, or received consulting or speaking fees, from: Alexza, Alkermes, AstraZeneca, Avanir, Bristol-Myers Squibb, Eli Lilly, Envivo, Forest, Genentech, Janssen, Lundbeck, Merck, Mylan, Novartis, Noven, Otsuka, Pfizer, Shire, Sunovion, and Valeant.

\section{References}

1. Citrome L. Agitation III: pharmacologic treatment of agitation. In: Glick RL, Berlin JS, Fishkind AB, Zeller SL, editors. Emergency Psychiatry: Principles and Practice. Baltimore, MD: Lippincott Williams and Wilkins; 2008:137-148.

2. Citrome L, Volavka J. Violent patients in the emergency setting. Psychiatr Clin North Am. 1999;22(4):789-801.

3. Nolan KA, Shope CB, Citrome L, Volavka J. Staff and patient views of the reasons for aggressive incidents: a prospective, incident-based study. Psychiatr Q. 2009;80(3):167-172.

4. Nolan KA, Volavka J, Czobor P, et al. Aggression and psychopathology in treatment-resistant inpatients with schizophrenia and schizoaffective disorder. J Psychiatr Res. 2005;39(1):109-115.

5. Nolan KA, Czobor P, Roy BB, et al. Characteristics of assaultive behavior among psychiatric inpatients. Psychiatr Serv. 2003;54(7):1012-1016.

6. Volavka J, Citrome L. Pathways to aggression in schizophrenia affect results of treatment. Schizophr Bull. 2011;37(5):921-929.

7. Volavka J, Citrome L. Heterogeneity of violence in schizophrenia and implications for long-term treatment. Int J Clin Pract. 2008;62(8): $1237-1245$.

8. Advokat C. A brief overview of iatrogenic akathisia. Clin Schizophr Relat Psychoses. 2010;3(4):226-236.

9. Citrome L, Krakowski M, Greenberg WM, Andrade E, Volavka J. Antiaggressive effect of quetiapine in a patient with schizoaffective disorder. J Clin Psychiatry. 2001;62(11):901.

10. Citrome L, Green L. The dangerous agitated patient. What to do right now. Postgrad Med. 1990;87(2):231-236.

11. Citrome L, Volavka J. Clinical management of persistent aggressive behavior in schizophrenia. Part I: definitions, epidemiology, assessment, and acute treatment. Essent Psychopharmacol. 2002;5(1):1-16.

12. Ahmed U, Jones H, Adams CE. Chlorpromazine for psychosis induced aggression or agitation [review]. Cochrane Database Syst Rev. 2010;4:CD007445.

13. Powney MJ, Adams CE, Jones H. Haloperidol for psychosis-induced aggression or agitation (rapid tranquillisation) [review]. Cochrane Database Syst Rev. 2012;11:CD009377.

14. Citrome L. Limited evidence on effects of haloperidol alone for rapid tranquillisation in psychosis-induced aggression. Evid Based Ment Health. 2013;16(2):47.

15. Vinogradov S, Fisher M, Warm H, Holland C, Kirshner MA, Pollock BG. The cognitive cost of anticholinergic burden: decreased response to cognitive training in schizophrenia. Am J Psychiatry. 2009;166(9):1055-1062.

16. Citrome L. Comparison of intramuscular ziprasidone, olanzapine, or aripiprazole for agitation: a quantitative review of efficacy and safety. $J$ Clin Psychiatry. 2007;68(12):1876-1885.

17. Wilson MP, Pepper D, Currier GW, Holloman GH Jr, Feifel D. The psychopharmacology of agitation: consensus statement of the American Association for Emergency Psychiatry Project Beta Psychopharmacology workgroup. West J Emerg Med. 2012;13(1):26-34.

18. US Food and Drug Administration. NDA Approval Letter, December 21, 2012. Silver Spring, MD: US Food and Drug Administration; 2012. Available from: http://www.accessdata.fda.gov/drugsatfda_docs/appl etter/2012/022549Orig1s0001tr.pdf. Accessed March 17, 2013.

19. Adasuve ${ }^{\circledR}$ (loxapine) inhalation powder, for oral inhalation use [prescribing information]. Mountain View, CA: Alexza Pharmaceuticals; 2012.
20. Alexza Pharmaceuticals. Alexza receives marketing authorization for Adasuve ${ }^{\circledR}$ (Staccato ${ }^{\circledR}$ loxapine) in the European Union [press release]. Mountain View, CA: Alexza Pharmaceuticals; 2013. Available from: http://phx.corporate-ir.net/phoenix.zhtml?c=196151\&p=irolnewsArticle\&ID=1787494. Accessed March 17, 2013.

21. Adasuve $e^{\circledR}:$ summary of product characteristics [webpage on the Internet]. Mountain View, CA: Alexza Pharmaceuticals; 2012. Available from: http://www.adasuve.com/index-eu.php. Accessed March 17, 2013.

22. Allen MH, Feifel D, Lesem MD, et al. Efficacy and safety of loxapine for inhalation in the treatment of agitation in patients with schizophrenia: a randomized, double-blind, placebo-controlled trial. J Clin Psychiatry. 2011;72(10):1313-1321.

23. Lesem MD, Tran-Johnson TK, Riesenberg RA, et al. Rapid acute treatment of agitation in individuals with schizophrenia: multicentre, randomised, placebo-controlled study of inhaled loxapine. $\mathrm{Br} J$ Psychiatry. 2011;198(1):51-58.

24. Kwentus J, Riesenberg RA, Marandi M, et al. Rapid acute treatment of agitation in patients with bipolar I disorder: a multicenter, randomized, placebo-controlled clinical trial with inhaled loxapine. Bipolar Disord. 2012;14(1):31-40.

25. Alexza Pharmaceuticals. Adasuve ${ }^{\circledR}$ (Loxapine) Inhalation Powder NDA 022549: Psychopharmacologic Drug Advisory Committee Briefing Document. Mountain View, CA: Alexza Pharmaceuticals; 2011. Available from: http://www.fda.gov/ downloads/AdvisoryCommittees/CommitteesMeetingMaterials/Drugs/ PsychopharmacologicDrugsAdvisoryCommittee/UCM282900.pdf. Accessed March 19, 2013.

26. US Food and Drug Administration. Adasuve ${ }^{\circledR}$ (Loxapine) Inhalation Powder NDA 022549: Psychopharmacologic Drug Advisory Committee Briefing Document. Silver Spring, MD: US Food and Drug Administration; 2011. Available from: http://www.fda.gov/ downloads/AdvisoryCommittees/CommitteesMeetingMaterials/Drugs/ PsychopharmacologicDrugsAdvisoryCommittee/UCM282897.pdf. Accessed March 19, 2013.

27. European Medicines Agency. Adasuve ${ }^{\circledR}$ Assessment Report. London: European Medicines Agency; 2012. Available from: http://www. ema.europa.eu/docs/en_GB/document_library/EPAR_-_Public_ assessment_report/human/002400/WC500139407.pdf. Accessed March 17, 2013.

28. Citrome L. Aerosolised antipsychotic assuages agitation: inhaled loxapine for agitation associated with schizophrenia or bipolar disorder. Int J Clin Pract. 2011;65(3):330-340.

29. Citrome L. Inhaled loxapine for agitation revisited: focus on effect sizes from two Phase III randomised controlled trials in persons with schizophrenia or bipolar disorder. Int J Clin Pract. 2012;66(3): 318-325.

30. Noymer P, Myers D, Glazer M, Fishman RS, Cassella JV. The Staccato ${ }^{\circledR}$ system: inhaler design characteristics for rapid treatment of CNS disorders. Respiratory Drug Delivery. 2010;1:11-20.

31. Dinh K, Myers DJ, Glazer M, et al. In vitro aerosol characterization of Staccato ${ }^{\circledR}$ loxapine. Int J Pharm. 2011;403(1-2):101-108.

32. Dinh KV, Myers DJ, Noymer PD, Cassella JV. In vitro aerosol deposition in the oropharyngeal region for Staccato ${ }^{\circledR}$ loxapine. JAerosol Med Pulm Drug Deliv. 2010;23(4):253-260.

33. Ereshefsky L. Pharmacologic and pharmacokinetic considerations in choosing an antipsychotic. J Clin Psychiatry. 1999;60(Suppl 10): 20-30.

34. Spyker DA, Munzar P, Cassella JV. Pharmacokinetics of loxapine following inhalation of a thermally generated aerosol in healthy volunteers. J Clin Pharmacol. 2010;50(2):169-179.

35. Amoxapine tablet drug label [webpage on the Internet]. Bethesda, MD: National Institute of Health; 2010. Available from: http://dailymed.nlm.nih.gov/dailymed/drugInfo.cfm?id=19651. Accessed November 12, 2010.

36. Citrome L. Compelling or irrelevant? Using number needed to treat can help decide. Acta Psychiatr Scand. 2008;117(6):412-419. 
37. Cassella J, Spyker D, Kwentus J, Lesem M, Fishman R. Rapid improvement in the five-item Positive and Negative Syndrome-Excited Component (PANSS-EC) scale for agitation with inhaled loxapine. 50th Meeting of the NCDEU; June 14-17, 2010; Boca Raton, FL, USA.

38. Citrome L. Quantifying risk: the role of absolute and relative measures in interpreting risk of adverse reactions from product labels of antipsychotic medications. Curr Drug Saf. 2009;4(3):229-237.

39. US Food and Drug Administration. Adasuve ${ }^{\circledR}$ (loxapine) Inhalation Powder: Risk Evaluation and Mitigation Strategy. Silver Spring, MD: US Food and Drug Administration; 2012. Available from: http://www.fda.gov/downloads/Drugs/DrugSafety/ PostmarketDrugSafetyInformationforPatientsandProviders/ UCM333242.pdf. Accessed March 17, 2013.
40. Citrome L, Nasrallah HA. On-label on the table: what the package insert informs us about the tolerability profile of oral atypical antipsychotics, and what it does not. Expert Opin Pharmacother. 2012;13(11):1599-1613.

41. Citrome L. Evidence-based medicine: it's not just about the evidence. Int J Clin Pract. 2011;65(6):634-635.

\section{Publish your work in this journal}

Therapeutics and Clinical Risk Management is an international, peerreviewed journal of clinical therapeutics and risk management, focusing on concise rapid reporting of clinical studies in all therapeutic areas, outcomes, safety, and programs for the effective, safe, and sustained use of medicines. This journal is indexed on PubMed Central, CAS,

Submit your manuscript here: http://www.dovepress.com/therapeutics-and-clinical-risk-management-journal
EMBase, Scopus and the Elsevier Bibliographic databases. The manuscript management system is completely online and includes a very quick and fair peer-review system, which is all easy to use. Visit http://www.dovepress.com/testimonials.php to read real quotes from published authors. 